\title{
Comparison of geometric proof development tasks as set up in the textbook and as implemented by teachers in the classroom
}

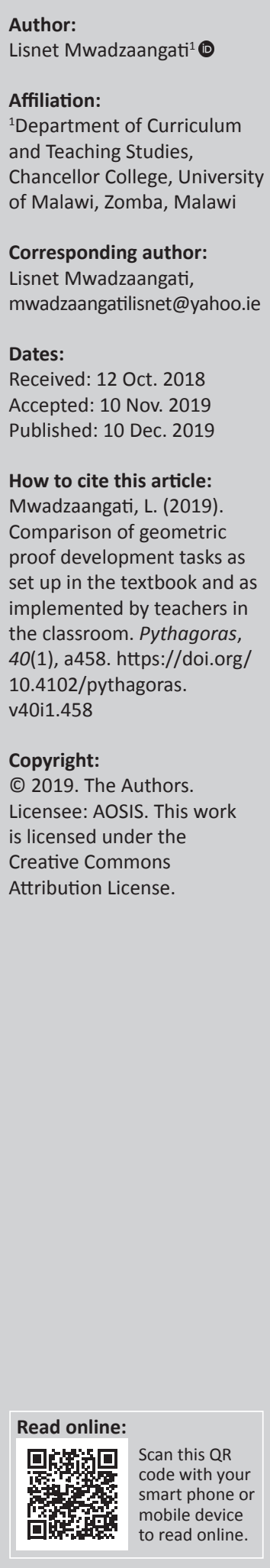

\begin{abstract}
This qualitative case study examined similarities and differences between circle geometric proof development tasks set up in the Malawian Grade 11 mathematics textbook, and those that are set up and implemented by teachers in the classroom. Data generation included analysing the content of circle geometry proof tasks from the mathematics textbook and video recordings of geometric proof development lessons taught by three teachers. The Mathematics Discourse in Instructional Framework for Textbook analysis (MDITx) by Ronda and Adler and the framework for analysing the level of cognitive demands of mathematical tasks by Smith and Stein were used to identify and analyse the mathematical tasks as set up by the textbook and as set up and implemented by three Malawian secondary school mathematics teachers in the classroom. The findings revealed that the textbook presented the geometric proof development tasks at a high level as they included both empirical exploration tasks and formal proof tasks. Despite this task setup in the textbook, only one teacher involved the learners in empirical exploration tasks and maintained the high cognitive level of the tasks during instruction. The other two teachers only presented the formal proof tasks. Although the formal proof tasks that were set up by the two teachers were of a high cognitive level, the procedures that were used during task implementation resulted in reduction of the cognitive level of the proof tasks. I therefore conclude that teachers' ability to set up and implement high cognitive level tasks that promote learners' understanding and discovery of deductive geometric proofs depends not only on the availability of a good quality textbook, but also on the teacher's conceptual ability to make effective use of textbook content.
\end{abstract}

Keywords: Task setup; task implementation; geometric proof development; mathematics textbook; geometric proof tasks.

\section{Introduction}

One of the aims of teaching secondary school mathematics in Malawi is to promote learners' logical reasoning, problem-solving and critical thinking skills (Ministry of Education, Science and Technology [MEST], 2013). Euclidean geometry is regarded as the main area of mathematics that is a key source for teaching mathematical argumentation and proof, developing learners' deductive reasoning and critical thinking (Kunimune, Fujita, \& Jones, 2010). But the Malawi National Examinations Board (MANEB) chief examiners' reports indicate that secondary school learners fail to develop geometric proofs at national examinations (MANEB, 2013). Poor teaching practices are highlighted as a major cause of learners' inability to understand geometric proof development (MANEB, 2013). The reports emphasise that due to lack of both content knowledge and pedagogical knowledge, the teachers are not creative in conducting effective lessons to support learners' understanding of geometric proof development. Studies conducted in different parts of the world also indicate that despite the importance of reasoning and proving in learners' learning, many learners face serious challenges in proof development (Kunimune et al., 2010; Otten, Males \& Gibertson, 2014; Stylianides, 2014). These studies support MANEB's by arguing that learners' challenges in proof development should be attributed more to classroom inappropriate practices that mainly emphasise rules of verification and devalue or omit exploration. As a result, the learners memorise the rules without understanding the process of proof development; hence, they are able to reproduce similar proofs but cannot apply the principles to develop a different proof (Ding \& Jones, 2009). Use of exploratory teaching strategies is suggested as one way of helping learners to understand geometric proof development (Ding \& Jones, 2009; Jones et al., 2009). This implies that the solution for improving classroom practices for enhancing learners' understanding of geometric proof development lies in teacher professional development and teacher education.

Stylianides (2014) argues that apart from teacher professional development and teacher education, textbooks are the other important but less explored and insufficiently exploited solution for 
improving classroom practices. This is because mathematics textbooks of a particular country often mirror the national curriculum (Fujita, Jones, \& Kunimune, 2009). As Ronda and Adler (2016) claim, 'textbooks have some similarity to classroom lessons - of course, without possibilities for actual (as opposed to imagined) contributions from learners in the development of the texts' (p. 1097). As such, many mathematics teachers use textbooks to decide the type of tasks to implement in class and the way of implementing such tasks; hence, mathematics textbooks have an influence on learners' opportunities in proof development (Stylianides, 2014). This might imply that availability of high cognitive demanding tasks in mathematics textbooks will always result in instructions that promote learners' understanding of geometric proof development. But Henningsen and Stein (1997) argue that, sometimes, a task could be set up in the textbook to require high-level cognitive demands from learners, but during classroom implementation phase it could be transformed in such a way that learners' thinking focuses only on procedures, with no conceptual connections. This implies that teachers' ways of setting up and implementing tasks might affect the cognitive level at which learners engage with the tasks.

This study builds on the findings from my PhD project (Mwadzaangati, 2017a) which aimed at exploring mathematical knowledge for teaching geometric proof development. What I found is that

most of the tasks that were used by the teachers were taken from secondary school mathematics textbooks and were presented in the form of either a statement or a diagram, or both statement and diagram. (Mwadzaangati, 2017a, p. 143)

One of the recommendations in my $\mathrm{PhD}$ dissertation was that future research should focus on comparing the textbook content on geometric proof development and the teachers' ways of implementing the textbook content. Therefore, this study aimed at examining similarities and differences between geometric proof development tasks (referred to as proof tasks hereafter) set up in the textbook, and those that are set up and implemented by the teacher in the classroom. In this study, task setup means the way tasks are presented either in the textbook or in the classroom. Specifically, this study aimed to answer the following two questions:

- What geometric proof development opportunities do proof tasks in Malawi secondary school mathematics textbooks offer to learners?

- How do opportunities in the proof tasks in the textbooks compare with opportunities in tasks that are set up and implemented by the teacher in the classroom?

\section{Significance of the study}

De Villiers (1999) distinguished six functions of proof as follows:

1. Verification (concerned with the truth of a statement)

2. Explanation (providing insight into why it is true)

3. Systematisation (the organisation of various results into a deductive system of axioms, major concepts and theorems)

4. Discovery (the discovery or invention of new results)
5. Communication (the transmission of mathematical knowledge)

6. Intellectual challenge (the self-realisation or fulfilment derived from constructing a proof). (De Villiers, 1999, p. 3)

The functions of mathematical proof that are suggested by De Villiers (1999) imply that teaching and learning of geometric proof focuses not only on learners' ability to verify mathematical statements, but also on their ability to explain why a certain mathematical statement is either true or false, argue in a logical manner, construct new knowledge and communicate their arguments. This implies that the teaching and learning of geometric proof development promotes some of the aims of teaching secondary school mathematics in Malawi such as logical reasoning, critical thinking and problem-solving. This means that teachers are expected to plan and implement proof tasks in a manner that would promote learners' opportunities to achieve the five functions of mathematical proof that are suggested by De Villiers. Since textbooks are the only resource that Malawian teachers use to plan and teach their lessons, it was necessary to compare the cognitive levels of proof tasks as set up in the textbook and as set up and implemented by the teacher during instruction.

\section{Literature review Geometric proof development}

Geometric proof development is a process of constructing a sequence of arguments from $X$ to $Y$ with supportive reasons, and hence is also called deductive reasoning and proving (Cheng \& Lin, 2009). $X$ is the given information (hypothesis) while $Y$ is the statement to prove (conclusion). Reasoning and proving are central to learning of geometric proof development because they offer learners opportunities to make sense of mathematics through pattern identification, generation of conjectures and development of arguments (Otten et al., 2014). Apart from formal proof development, deductive reasoning and proving support learners' capabilities in other mathematical elements including developing, outlining, or correcting an argument, deriving a formula, making or testing a conjecture (Bergwall, 2017).

It is, however, reported that many learners experience challenges in deductive geometric proof development (Battista, 2007; Kunimune et al., 2010; Otten et al., 2014; Stylianides, 2014). Several reasons have been advanced for this problem. Usiskin (1982) argued that learners do not succeed in secondary deductive geometric proof development because their prior knowledge in the geometry course is poor. He claimed that the learners come to learn secondary geometry before they have reached the level of formal deduction that was proposed by Van Hiele (1999).

Jones (2002) noted three reasons for learners' difficulties in learning to develop geometric proofs. Firstly, the learning of geometric proving is complex because it requires coordination of a range of competencies. Secondly, the teaching approaches used during geometric proving lessons tend to concentrate on verification and devalue, or omit, exploration and 
explanation of how and why the proof works. Thirdly, learning to prove involve learners' ability in making the difficult transition from informal geometric reasoning to formal deductive geometric reasoning. Jones (2002) argued that these reasons imply that teachers find it difficult to provide learners with meaningful experiences to enable them to understand geometric proof development. Battista (2007) explained that geometric proof development continues to be challenging to learners because it involves geometric reasoning which mainly requires spatial reasoning. As such, learners face challenges in using spatial reasoning to see, inspect, and reflect on spatial objects, images and relationships (Battista, 2007). Heinze (2004) identified three reasons why learners fail to develop geometric proofs. These include insufficient knowledge of facts and concepts for developing the proof, deficits in methodological knowledge about mathematical proofs, and lack of knowledge with respect to developing and implementing a proof strategy.

This brief review has shown that there are two major causes of learners' challenges in geometric proof development. The first challenge lies in the nature of geometric proof development itself as being a complex domain. The second reason is use of inappropriate teaching and learning strategies which prolong learners' challenges in understanding a domain that is already complex. This implies that the solution for this challenge lies in teachers' ability to provide learners with meaningful experiences for understanding geometric proof development. This study argues that teachers' ability to set up and implement high cognitive level tasks is an interplay of many factors including the type of curriculum material available to the teachers as well as the teachers' ability to make effective use of these materials.

\section{Design and use of mathematics textbooks in Malawi}

Malawian textbooks are expected to mediate both the intended and the implemented curriculum. As such the national curriculum determines the content of textbooks of a particular educational level in Malawi. This is because textbooks are the main content resource used by teachers in Malawi just like in other developing countries which are characterised by lack of teaching and learning resources (Ronda \& Adler, 2016). This implies that textbook design is expected to determine the teaching and learning of a particular subject or concept to a greater extent. Malawian public secondary school textbooks writers and publishers are commissioned by MEST. Purchasing and supplying textbooks into public secondary schools is also authorised by MEST. As such, textbooks that are available in Malawian public secondary schools are only those that are recommended and supplied by MEST. For secondary school mathematics education, there are two types of textbooks that were recommended by MEST for use in the secondary schools. The content of these mathematics textbooks combines all branches of mathematics at secondary school mathematics level in Malawi including geometry, algebra and arithmetic. Teachers are expected to decide whether to use either both textbooks or only one textbook depending on the content. As Mellor, Clark and Essien (2018) noticed, two different textbooks can present the same topic in different ways, hence creating different affordances for learners to learn the topic. The two textbooks that are recommended by MEST are written for both teachers and learners. The teachers are expected to be guided by the two recommended mathematics textbooks when planning and implementing their lessons.

\section{The Van Hiele levels of geometric thought}

According to Van Hiele (1999), learners progress through five levels when learning geometry. These are visualisation, analysis, informal deduction, formal deduction and rigour (Van Hiele, 1999). Geometric proving starts from the informal deduction level. Learners at informal deduction level can deduce properties of a shape, recognise classes of shapes and follow formal proofs, but they do not know how to construct a proof starting from different or unfamiliar premises (Crowley, 1987). At formal deduction level, learners can develop a proof in more than one way, because they understand the interaction of necessary and sufficient conditions of a proof (Crowley, 1987). Van Hiele explains that most of the secondary school geometry is at the formal deduction level. The Van Hiele levels of geometric thought have a sequential and advancement property. The sequential property is linear and hierarchical; as such, learning and attainment of higher levels always depends on attainment of the lower levels (Crowley, 1987). The advancement property implies that progress or lack of progress from one level to the next level depends more on the content and methods of instruction received rather than the age of the student (Crowley, 1987). If a method only helps a student to memorise geometric concepts without understanding, it reduces the learners' ability to progress to the higher level (Crowley, 1987). This means that learners' challenges in geometric proof development which is at formal deduction level might be a result of the quality of content and methods that are used by the teachers. The advancement property of the levels also implies that learners' challenges in geometric proof development might affect their advancement to the next level of geometric thought. As already indicated, the main source of content and methods for Malawian teachers is the textbook; therefore, a study on textbooks and teachers was necessary.

\section{Studies on geometric proof development textbooks}

Well-designed mathematics textbooks are regarded as a good resource for supporting learners to understand reasoning and proving (Thompson, Senk, \& Johnson, 2012). Textbooks mediate between the intended and the implemented curriculum; hence, they are widely used in classrooms around the world (Fujita et al., 2009). Mathematical tasks presented in the textbooks offer potential sources for opportunities to learn reasoning and proving (Bergwall, 2017). Thus, the learning of mathematics can be influenced by the textbook content (Mellor et al., 2018). This influence might be greater in developing countries where textbooks 
remain the most readily available resource due to constraints of teaching and learning resources (Ronda \& Adler, 2016). Due to the widely agreed upon importance of textbooks to learners' learning, many scholars have called for studies on how proofs are presented in textbooks (Fujita et al., 2009; Ronda \& Adler, 2016; Stylianides, 2014).

Otten, Gilbertson, Males and Clark (2011) examined the reasoning and proving activities, justifications given, as well as the nature of mathematical statements around which reasoning and proving take place in six US secondary textbooks. They found that the mathematical content of the exposition part of the textbook was general in nature; for example, they generalised how to prove properties of a particular shape like a rectangle, but the content of the exercise tasks was specific to a mathematical concept, for example finding values of angles. Otten et al. (2011) concluded that although the textbooks contained many theorems and proofs, there were rare tasks that asked the learners to develop the proof on their own. Most of the tasks required the learners either to provide a rationale or to determine the truth value of a mathematical claim but not to provide a deductive argument.

Fujita et al. (2009) analysed the content of the textbooks commonly used for teaching learners geometric proof development in lower secondary school in Japan. They found that deductive reasoning is prominent in Japanese textbooks as expected from the curriculum specification. However, the Japanese textbooks only presented geometric proof development in a formal way without convincing illustrations that can help learners to understand the difference between formal proof and experimental proof. Fujita et al. (2009) claim that this type of geometric proof presentation in the textbook might only help the learners to understand the process of geometric proof development but not to understand and appreciate its discovery function; hence, they are unable to understand the notion of generality as well. This agrees with De Villiers (1999) who identified discovery or invention of a new mathematical result as one of the functions of mathematical proof. Fujita et al. (2009), therefore, suggested that textbooks should design geometric proof development in a manner that provide learners with opportunities that can help them to understand and appreciate more fully the notion of generality of proof. Bowie (2013) analysed a Grade 10 South African textbook chapter on quadrilaterals to find out how it managed tensions inherent in transition between informal and formal geometry. She found that in some instances, the book used tightly prescribed investigations, generalisations and definitions to manage the transition. This implied that the textbooks struggled with the transition from informal to formal geometry.

Thus, this review has shown that analysis of textbooks in relation to geometric proof development has focused on different issues. These include illustration of differences between experimental verification and formal proof (Fujita et al., 2009), proof presentation (Otten et al., 2014), mediating of transition between informal and formal geometry (Bowie, 2013; Thompson et al., 2012), significance and methodological challenges of analysing reasoning and proving in textbooks (Stylianides, 2014), proof and proving in general (Stylianides, 2009). While the focus of previous studies was on the content and tasks set up in the textbooks and their affordances to reasoning and proving only, this study focuses on both geometric proof task setup in textbooks as well as task setup and implementation in the classroom.

\section{Theoretical framework}

The study is guided by two analytical frameworks: Mathematics Discourse in Instructional analytic framework for textbook analysis (MDITx) developed by Ronda and Adler (2016) and mathematical task analysis framework developed by Smith and Stein (1998). The MDITx framework comprises five key elements: object of learning, examples, tasks, naming and word use and legitimations. The object of learning is what the learners are expected to be able to do at the end of the lesson (Ronda \& Adler, 2016). In this study, the object of learning was developing geometric proofs. Examples are a particular case of a larger class used for drawing reasoning and generalisations (Ronda \& Adler, 2016). Learners' textbooks are expected to contain an example space (set of examples) which would enable the learners to attend to a particular feature of the object of learning. A mathematics textbook can contain two types of example spaces: worked example spaces and example exercise spaces (Ronda \& Adler). Worked examples are those whose solutions are provided, while exercises examples are those whose solutions are not provided by the textbook or the teacher. Tasks are what learners are asked to do with the examples like solving, proving, measuring or drawing (Ronda \& Adler). Naming and word use is the way of naming mathematical concepts. Adler and Ronda (2015) argue that the specific words that we use for naming mathematical concepts and the way we name the procedures or actions carried out on them affect learners' attention in particular ways. Legitimations are the mathematical and nonmathematical criteria that are communicated to substantiate the key steps in procedures or in statements about the object of learning. This study used three MDITx elements: (1) object of learning, (2) examples and (3) tasks, to partition the content in a circle geometry chapter of a textbook. The MDITx framework was used for analysing both textbook and lesson observation data because the ways of identifying these three elements (object of learning, examples and tasks) in the textbook and in the lesson is similar (Adler \& Ronda, 2015; Ronda \& Adler, 2016). However, although the MDITx framework contains different levels for analysing cognitive level of tasks, it does not focus on how to analyse the implementation of the tasks. Therefore, a framework by Smith and Stein (1998) was used for analysing the cognitive level at which the tasks were implemented by the teachers.

The mathematical task analysis framework by Smith and Stein (1998) comprises four categories of cognitive demands of a task: (1) memorisation, (2) procedures without connections to concepts or meaning, (3) procedures with 
connections to concepts and meaning, and (4) doing mathematics. The categories of tasks depend on the level of learners' thinking; hence they offer learners different opportunities of learning depending on the level of the thinking involved and the activities expected in each category. Memorisation tasks involve exact reproduction of previously learnt facts without showing their algorithms, for example listing the properties of a rectangle. Procedures without connections to concepts or meaning are tasks that require the use of an algorithm without showing understanding of how the algorithm works (Smith \& Stein, 1998). An example of procedure without connections is using given information to come up with statements for proving that two triangles are congruent. Memorisation and procedures without connections are classified under lower-level tasks because they place little demand on learners' thinking and explanations. Procedures with connections to concepts require some degree of cognitive effort because they involve thinking about how to apply a procedure to a task (Smith \& Stein, 1998). An example of a procedure with connections task might involve developing a multi-step proof that requires learners to apply several geometric properties. Doing mathematics tasks also demands considerable cognitive effort because the procedure is not known to the learners, so they are required to explore and understand the nature of mathematical concepts, processes, or relationships to be used in solving the task. An example of a doing mathematics tasks might involve exploring a geometric theorem and its proof both empirically and formally to understand how and why it works. This study used Smith and Stein's mathematical task analysis framework as a guide for analysing cognitive changes as the geometric tasks passed through different phases from the textbook to the classroom. As Stein, Glover and Henningsen (1996) point out, a task can be viewed as passing through three phases: firstly, as curricular or instructional materials (textbook), secondly, as set up by the teacher in the classroom and, thirdly, as implemented by learners during the lesson. As such, Smith and Stein's framework of analysing tasks was used and acted as a lens for analysing the cognitive level of geometric proof development tasks as they passed through these three phases.

\section{Research methods and design}

The study utilised a qualitative case study design with the aim of gaining in-depth understanding of the issue being studied as in line with Yin (2009). Data for the study were generated through qualitative content analysis of a secondary school mathematics textbook and lesson observations. One textbook, Strides in mathematics 3, which was written by Hau and Saiti (2002), was analysed because it was the only textbook that was being used by all the teachers who participated in the study. Deductive proof tasks and examples on nine circle geometry theorems were analysed to examine their cognitive level. To find out how teachers set up and implemented the geometric proof development tasks in the classroom, I analysed lessons by three teachers for Form 3 mathematics. This is part of the data that I collected and analysed for my PhD study. The three teachers taught the entire topic of circle geometry at secondary level as prescribed in the curriculum. In total, I observed and videorecorded 43 lessons from these teachers. The three teachers were from three different government funded secondary schools. The teachers, Paul, John and Kim (pseudonyms), were purposively selected on the condition that they were qualified teachers with a minimum of a Bachelor of Education degree and teaching experience of six years. The assumption for selecting such teachers was that by the end of six years, the teachers would be familiar with the content of the recommended mathematics textbooks and would have selected what they considered to be the best textbooks for their teaching. In Malawi, secondary education is four years and beginning teachers (teachers with less than three years of teaching experience) are usually allocated junior secondary classes (Grade 9 and Grade 10) while experienced teachers are allocated senior classes (Grade 11 and Grade 12). As such, the teachers would have acquired experience in selecting and implementing deductive geometric proof tasks and examples by the end of six years.

\section{Data analysis}

Geometric task as set up in the textbook is the way the task is presented as well as how the learners are expected to engage with the task. Geometric task as set up by the teacher is the way the task is presented by the teacher in the classroom, which can be either in elaborate form (including verbal directions and explanations) or short and simple form (such as telling the learners to begin work on a set of problems displayed on the chalkboard). Task implementation is the manner in which learners actually work on the task (Stein et al., 1996). Analysis of lesson observation data involved transcribing the video recordings, identifying units of analysis (segments with deductive geometric proof development tasks and their implementation) and analysing the cognitive level of the task setup and task implementation.

Identification of the object of learning, the examples and the tasks as set up in the textbook, and as set up by the teacher in the classroom, was done by using the MDITx analytical framework suggested by Ronda and Adler (2016). Analysis of the cognitive level of the tasks as set up and as implemented by the teacher in the classroom was done by using the Stein et al. (1996) framework. Analysis of the textbook data involved several steps. As the circle geometry chapter is already partitioned into sections according to the theorems covered, the first step was to partition each circle geometry theorem section into object of learning, examples and tasks using the MDITx analytical framework. The second step involved identification of deductive geometric proof development tasks which were the main focus of the study. The third step involved examining what each task required of the learners and relating the requirements to the four categories of cognitive demands to determine their cognitive level using Stein et al.'s analytical framework. To ensure credibility of the findings, the transcribed lesson observation and textbook data were also analysed by another researcher and the differences and similarities were discussed. The issue 
of transferability was addressed by providing thick descriptions on how data was collected and analysed (Bryman, 2008). To ensure dependability of the findings, the records of all phases of the research process were kept in accessible form (Bryman, 2008).

\section{Ethical considerations}

During data collection and analysis, I observed several schoolbased research ethical principles proposed by Cohen, Manion and Morrison (2007) and Berg (2001). These included following official protocol to gain access and acceptance into the school (Cohen et al., 2007), informed consent, and the issue of confidentiality (Berg, 2001). Prior to going to the schools, I received approval from my supervisory committee permitting me to conduct a study with at least three secondary school teachers who were teaching circle geometry during the period of data collection. To gain access into the schools, I obtained an introductory letter from the department where I was studying to the Education Division Manager. Upon approving the request to conduct a study in the said secondary schools, the Education Division Manager granted me a permission letter addressed to the head teachers and mathematics teachers of the schools. To seek informed consent from each teacher, I followed several steps (Berg, 2001). Firstly, I explained to each teacher the purpose of my study and how I was going to conduct the study. Secondly, I assured the teacher that they would be treated anonymously during reporting, as pseudonyms would be used instead of real names. Thirdly, I assured the teachers that the data collected from their classrooms would only be used for purposes of this study and be treated confidentially. Consent to observe the teachers' lessons was sought every day before going to the classroom.

\section{Research findings}

The findings are presented in three subsections:

- tasks as set up by the textbook

- tasks as set up by the teacher in the classroom

- task implementation by the teachers.

\section{Analysis of tasks as set up by the textbook}

There are nine circle geometry theorems in the textbook. Two theorems are on chord properties of the circle, three theorems are on angle properties of chords in the circle, two theorems are on properties of cyclic quadrilaterals, and two theorems are on concyclic points of a circle. In summary, analysis of the tasks set up for the nine theorems show that learners were expected to do two types of tasks on each circle geometry theorem. Firstly, they were expected to do an empirical exploration task where they were to draw a geometric diagram, do some measurements, and then deduce a theorem. Secondly, they were expected to develop a formal proof for each theorem that was deduced from the empirical exploration task. At the end of these tasks, the formal proof is given, but the textbook emphasises that the learners should first attempt to develop the formal proofs on their own and then compare their proofs to those given it the textbook.
There are two limitations in terms of the way empirical tasks are presented in the textbook. The first limitation is that there is one instance where the textbook begins with a formal proof task then moves to an empirical exploration task. This strategy is not supported by some researchers who argue that learners should first be engaged in an empirical exploration before learning a formal proof to enhance their understanding of how and why the formal proof works (Ding \& Jones, 2009; Jones et al., 2009; Stylianides, 2005). The second limitation is that for all empirical tasks, the learners are asked to draw one diagram, measure its angles or lines, and deduce a theorem from the results of a single case. There is only one empirical exploration task where learners are expected to draw several diagrams or generalise from multiple cases. This shows that most of the empirical exploration tasks that are set up in the textbooks do not conform to some mathematical principles which discourage generalising from a single case (Marton \& Tsui, 2004). Despite the limitations, the tasks that are set up in the textbook can be regarded as of high cognitive level because they promote engagement of learners in both an empirical exploration task and formal proof task.

Some examples of the empirical exploration tasks set up in the textbook are shown in Figure 1, Figure 2 and Figure 3.

\section{Empirical task on chord properties of the circle}

Figure 1 presents the empirical task on chord properties of the circle.

According to the MDITx analytical framework, the section title in Figure 1 shows that the object of learning is chord properties of the circle. Although the activity is titled as 'challenge', I partitioned this segment under example exercise because it is a particular case from which learners are expected to deduce or generalise that a perpendicular line drawn from the centre of the circle to a chord bisects the chord (Ronda \& Adler, 2016). The task is for the learners to first try to develop a formal proof to show that $A X=X B$ and then afterwards verify empirically that $A X=X B$. It is noted that the textbook does not provide clear guidelines regarding the type of resources to be used for drawing the diagrams. This might be the case because the mathematics books that the teachers and learners use in Form 1 (Grade 9) provide clear guidelines on construction and drawing of geometric diagrams. Therefore, at this level, the learners already know the materials to use when drawing a geometric diagram. In Figure 1 the learners are required to follow the given procedure to draw a circle with a chord and to drop a

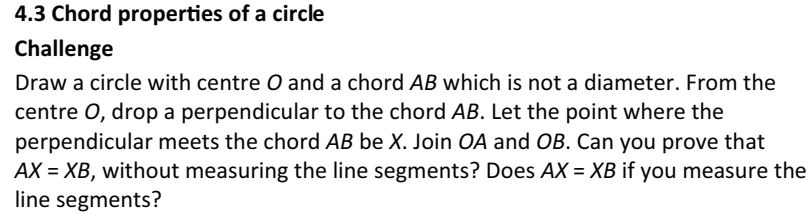

Source: Adapted from Hau, S., \& Saiti, F. (2002). Strides in mathematics 3. Balantyre: Longman Malawi (p. 27)

FIGURE 1: Empirical task on chord properties of the circle. 


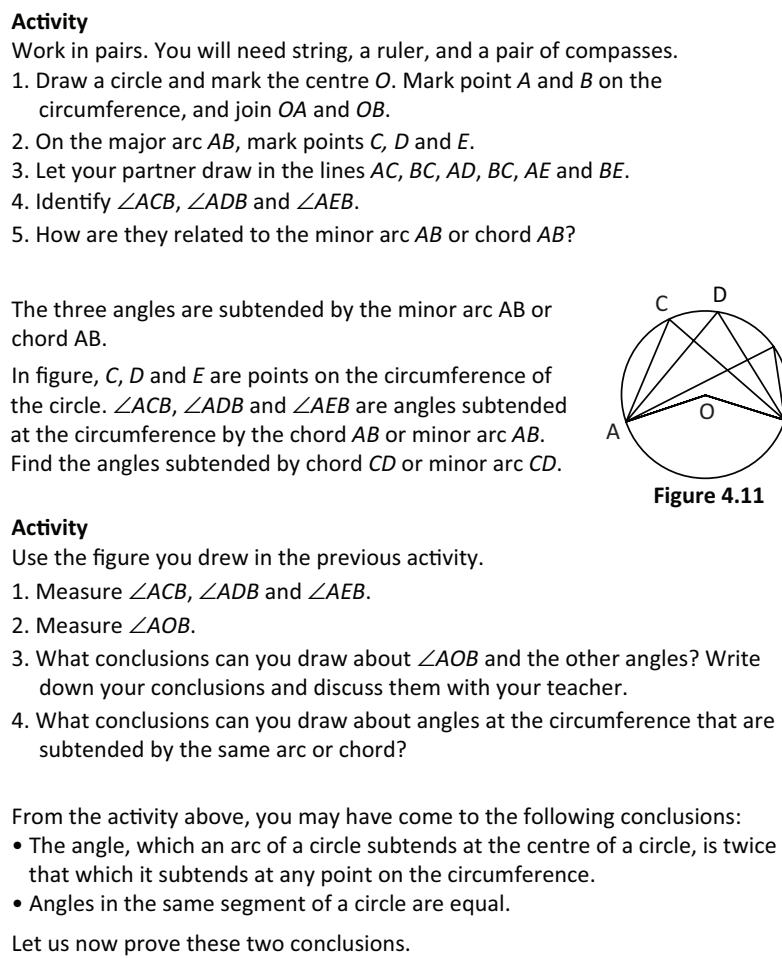

The three angles are subtended by the minor arc $A B$ or chord $A B$.

In figure, $C, D$ and $E$ are points on the circumference of the circle. $\angle A C B, \angle A D B$ and $\angle A E B$ are angles subtended at the circumference by the chord $A B$ or minor arc $A B$. Find the angles subtended by chord $C D$ or minor arc $C D$.

\section{Activity}

Use the figure you drew in the previous activity.

1. Measure $\angle A C B, \angle A D B$ and $\angle A E B$.

2. Measure $\angle A O B$.

3. What conclusions can you draw about $\angle A O B$ and the other angles? Write down your conclusions and discuss them with your teacher.

4. What conclusions can you draw about angles at the circumference that are subtended by the same arc or chord?

From the activity above, you may have come to the following conclusions:

- The angle, which an arc of a circle subtends at the centre of a circle, is twice

that which it subtends at any point on the circumference.

- Angles in the same segment of a circle are equal.

Let us now prove these two conclusions.

Source: Adapted from Hau, S., \& Saiti, F. (2002). Strides in mathematics 3. Balantyre: Longman Malawi (p. 29)

FIGURE 2: Empirical task on angle properties of the circle.

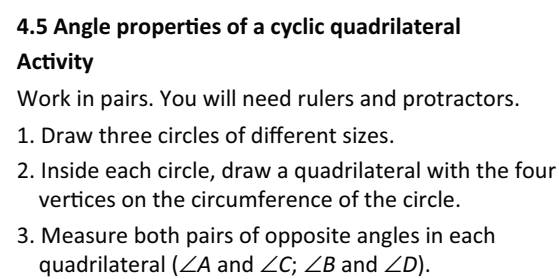

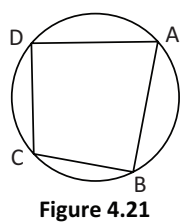

Figure 4.21
What do you notice about the sum of the measures of the opposite angles in each case?

Source: Adapted from Hau, S., \& Saiti, F. (2002). Strides in mathematics 3. Balantyre: Longman Malawi (p. 32)

FIGURE 3: Empirical task on angle properties of a cyclic quadrilateral.

perpendicular from the centre of the circle to a chord. Using the diagram that they draw, the learners are required to think of ways of developing a proof to show that a perpendicular line drawn from the centre of the circle bisects the chord. Although a hint is provided regarding the construction to be made (join $O A$ and $O B$ ), the task is under the doing mathematics category because it requires learners to identify another hint (in this case a theorem) for developing the proof (Stein, Smith, Henningsen, \& Silver, 2009). As Cheng and Lin (2009) argue, the most critical part of geometric proof development is hypothetical bridging which involves identifying or constructing a theorem that can link the hypothesis and the conclusion.

The task in Figure 1 shows that the textbook promotes engagement of learners in both formal and empirical understanding of the proof. Two limitations of empirical exploration task setup are observed in Figure 1. The first limitation is that the learners will be required to generalise from a single case since only a single diagram will be used to deduce the theorem. The second limitation is that the learners will begin by developing a formal proof then do the empirical exploration task. This means that the empirical task will be used for the purpose of verification but not for discovery of a proof, hence it might not promote learners' understanding of geometric proof development.

\section{Empirical exploration task on angle properties of the circle}

Figure 2 presents empirical exploration tasks that learners are expected to carry out before learning the formal proof development on angle properties of chords in a circle.

The object of learning for the empirical tasks in Figure 2 is angle properties of chords in a circle. There are two empirical tasks that learners are required to do before developing a formal proof. I also partitioned these activities under example exercise because they aim at helping learners to come to two generalisations or conclusions (Ronda \& Adler, 2016). The first generalisation as stated in the textbook is that 'the angle, which an arc of a circle subtends at the centre of a circle, is twice that which it subtends at any point on the circumference' (Hau \& Saiti, 2002, p. 29). Although the focus of this study was not on naming or word use, it is worth commenting that the way the textbook has stated the theorem implies that it does not matter whether the angles are in the same segment or not. For example, it might mean that the angle size of reflex $\angle A O B$ is equal to twice the size of either $\angle A C B$ or $\angle A D B$ or $\angle A E B$. But for the theorem to be true, the angles are supposed to be in alternate segments. For example, in the case of the diagram produced in Figure 1, it is the size of the obtuse $\angle A O B$ which is equal to twice the size of either $\angle A C B$ or $\angle A D B$ or $\angle A E B$ on the circumference. The correct way of stating the theorem would be: the angle that an arc of a circle subtends at the centre of a circle is twice the angle that it subtends at any point on the circumference in the alternate segment. This implies that the textbook has not stated the theorem in a correct manner; as such, if the teachers do not notice this mistake, they might not phrase the theorem correctly during the proving lesson.

The second generalisation as stated in the textbook is that 'angles in the same segment of a circle are equal' (Hau \& Saiti, 2002, p. 29). Figure 2 shows that Activity 1 requires learners to draw a diagram according to the given steps and recognise that $\angle A C B$ or $\angle A D B$ or $\angle A E B$ are produced by a common chord $A B$, hence they are named as angles in the same segment of a circle. Activity 2 requires learners to measure the angles $(\angle A C B, \angle A D B$ and $\angle A E B)$, identify relationships between or among these angles, and deduce a theorem that angles in the same segment of a circle are equal. Thus Activity 1 and Activity 2 require the learners to do several tasks, for example drawing, measuring, relating angles and deducing theorems. Although the limitation of generalising from a single case is also observed on exploration tasks in Figure 2, both tasks are under the doing mathematics category because they require learners to explore the diagram 
in relation to the values they get and to deduce theorems that they will be required to discuss with their teacher. This implies that the learners would be engaged in making connections between their findings and the lines drawn on the diagram and to justify their conclusions. After doing the measuring activity and drawing conclusions, the learners are expected to learn how to develop the formal proof. This way of sequencing geometric proof development tasks supports learners' understanding of the difference between empirical proof and formal proof, and it also promotes learners' understanding of formal proof (Ding \& Jones, 2009; Jones et al., 2009; Stylianides, 2005).

\section{Empirical task on angle properties of a cyclic quadrilateral}

Figure 3 presents the task on angle properties of a cyclic quadrilateral.

As shown by the section title, the object of learning for the activity in Figure 3 is angle properties of a convex cyclic quadrilateral. I partitioned the activity in Figure 3 under example exercise because it aimed at helping learners to deduce or generalise that opposite angles of a convex cyclic quadrilateral are supplementary. Thus, the task for this example required learners to do an empirical exploration by following the three steps that have been provided in Figure 3. This implies that the task in Figure 3 is also under the doing mathematics category because it requires learners to make explorations and use the empirical results to deduce a theorem (Smith \& Stein, 1998). The task in Figure 3 is an example of an empirical task that takes into account the mathematical principle of generalising from several sets of examples (Marton \& Tsui, 2004; Ronda \& Adler, 2016).

The study found that all the circle geometry theorems in the textbook that were analysed used a similar approach. There is an empirical activity that learners are expected to do before developing the formal proof. However, there is one instance where the learners are expected to develop a formal theorem before doing an empirical exploration. All empirical exploration tasks require learners to do different mathematical activities including drawing diagrams, doing measurements on the diagram, identifying geometric relationships between or among different parts of the diagram, and deducing theorems based on the findings. After doing each empirical exploration task, the learners are expected to reflect on the inductive proof to develop a deductive geometric proof without any given hints on theorems or geometric properties to be applied. As such, the learners are expected to devise their own strategies of developing the proof. In the course of devising the strategies, the learners might develop new problem-solving skills. This shows that the inductive proof that learners develop through empirical activities and the deductive proof that they later develop might enhance learners' abilities not only to verify the theorem, but also to discover new knowledge and new ways of problem-solving (De Villiers, 2012; Ding et al., 2009). This also means that the deductive geometric proof development tasks set up in the textbook are in the doing mathematics category, hence they are of high cognitive demand (Stein et al., 2009). As such, the tasks that are set up in the textbook have the potential to engage the learners in making connections among different features of geometric content (Ronda \& Adler, 2016), to link formal and informal geometry (Bowie, 2013), and to make logical and clear explanations (deductive proving), hence promoting other functions of proof like explaining and justifying mathematical concepts (De Villiers, 2012).

\section{Analysis of tasks as set up by the teachers in the classroom}

The findings showed that deductive geometric proof development task setup and implementation by teachers in classrooms was slightly different. It was observed that Paul and John set up formal proof tasks only during all proving lessons for the nine theorems on deductive proof development. Kim always started from an empirical exploration task to formal proof task in all proving lessons for the theorems.

\section{Empirical tasks set up by Kim in the classroom}

Figure 4 and Figure 5 present some of the empirical tasks set up by Kim in the classroom before presenting the formal proof task.

Both Figure 4 and Figure 5 show example exercises that the learners were asked to do in class. The main object of learning for the examples and tasks in Figure 4 was proving the theorems about the chord properties of a circle. The specific object of learning for Activity 1 in Figure 4 was discovering that a perpendicular line drawn from the centre of the circle bisects the chord of the circle, while the object of learning for Activity 2 was proving that if a line drawn from the centre of a circle bisects the chord, then the line is perpendicular to the chord. The tasks for both examples required learners to measure either lines or angles and deduce theorems based on the results of empirical exploration tasks.

Figure 4 shows that the learners were expected to draw a circle with a perpendicular line from the centre of the circle to chord, measure lines $A D$ and $B D$, compare lengths of the lines, and deduce a theorem. The task setup in Figure 4 is similar to the task setup in the textbook (Figure 1). However, in addition to the textbook example, Kim set up example 2 where learners are required to draw another chord whose length is equal to the first chord, draw a perpendicular line from the centre of the circle to the chord, compare its length to the first perpendicular line, and then deduce a theorem. Kim might have extended example 1 to ensure that both chord properties of the circle that were being proved during the lesson are deduced and tested using empirical explorations.

The object of learning for the task in Figure 5 is proving that angles in the same segment are equal. As such the learners are expected to do a similar empirical exploration task of drawing a circle with several angles subtended by the same arc, measuring the angles, and deducing a theorem from the results. However, the task is slightly different from the one in 


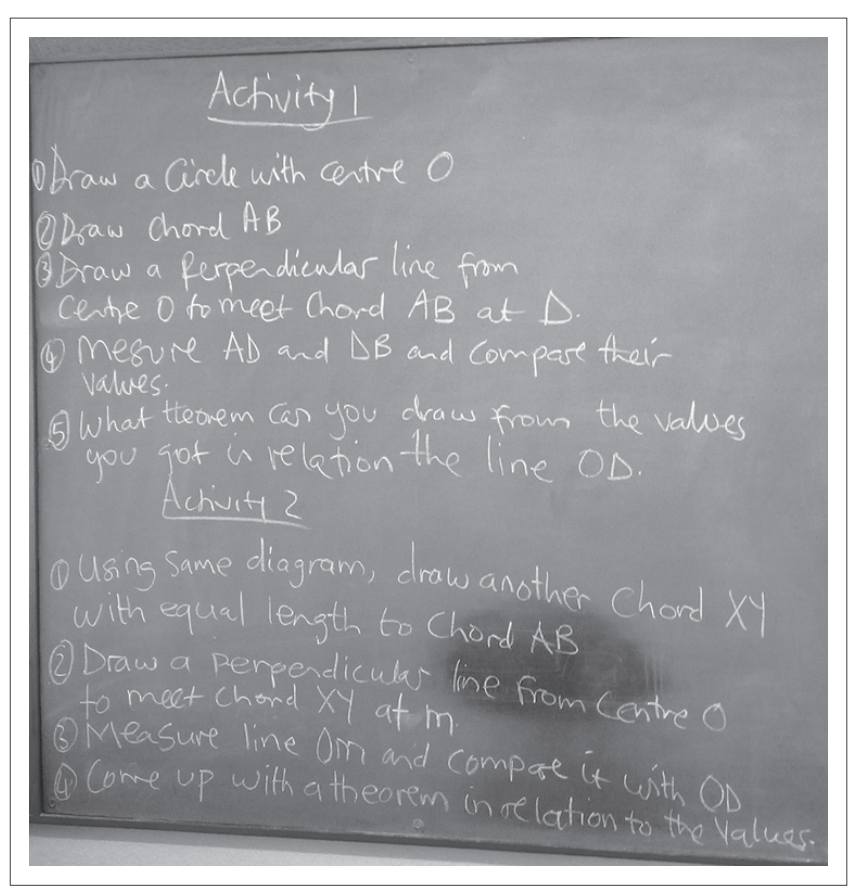

Note: Kim's observation data

FIGURE 4: Empirical exploration tasks on chord properties of the circle.

Figure 2 as it is only concerned with angles in the same segment of the circle. This might also be the case because on this day the object of learning was only about angles in the same segment.

Although the limitation of generalising from a single case is also observed in Kim's exploration tasks, there is an attempt to use the exploration approach that is suggested in the textbook. In general, the tasks set up by Kim can be categorised under the doing mathematics category as they required learners to make explorations and discoveries in reference to the results from empirical explorations. Figure 4 and Figure 5 also show that Kim made some modifications to the textbook activities according to the theorem that was being explored on a particular day, as well as to ensure that learners discovered each theorem on their own using empirical evidence.

\section{Formal deductive geometric proof development tasks as set up by the teachers in the classroom}

The findings showed that most of the formal proof tasks set up by the three teachers in the classroom were similar and they were taken from the same textbook (Strides in mathematics 3). The similarity of the tasks might suggest that the teachers made either few or no alterations on the textbook tasks. Figure 6(a) and Figure 6(b) present examples and tasks set up by the teachers in the classroom for development of formal deductive geometric proofs. The tasks were set up for proving a third theorem on circle geometry and were from lesson number 3.

Figure 6(a) and Figure 6(b) show that the tasks are similar despite differences in the way the diagrams are drawn. The tasks involve developing a formal deductive geometric proof to show that angles in the same segment of a circle are equal.

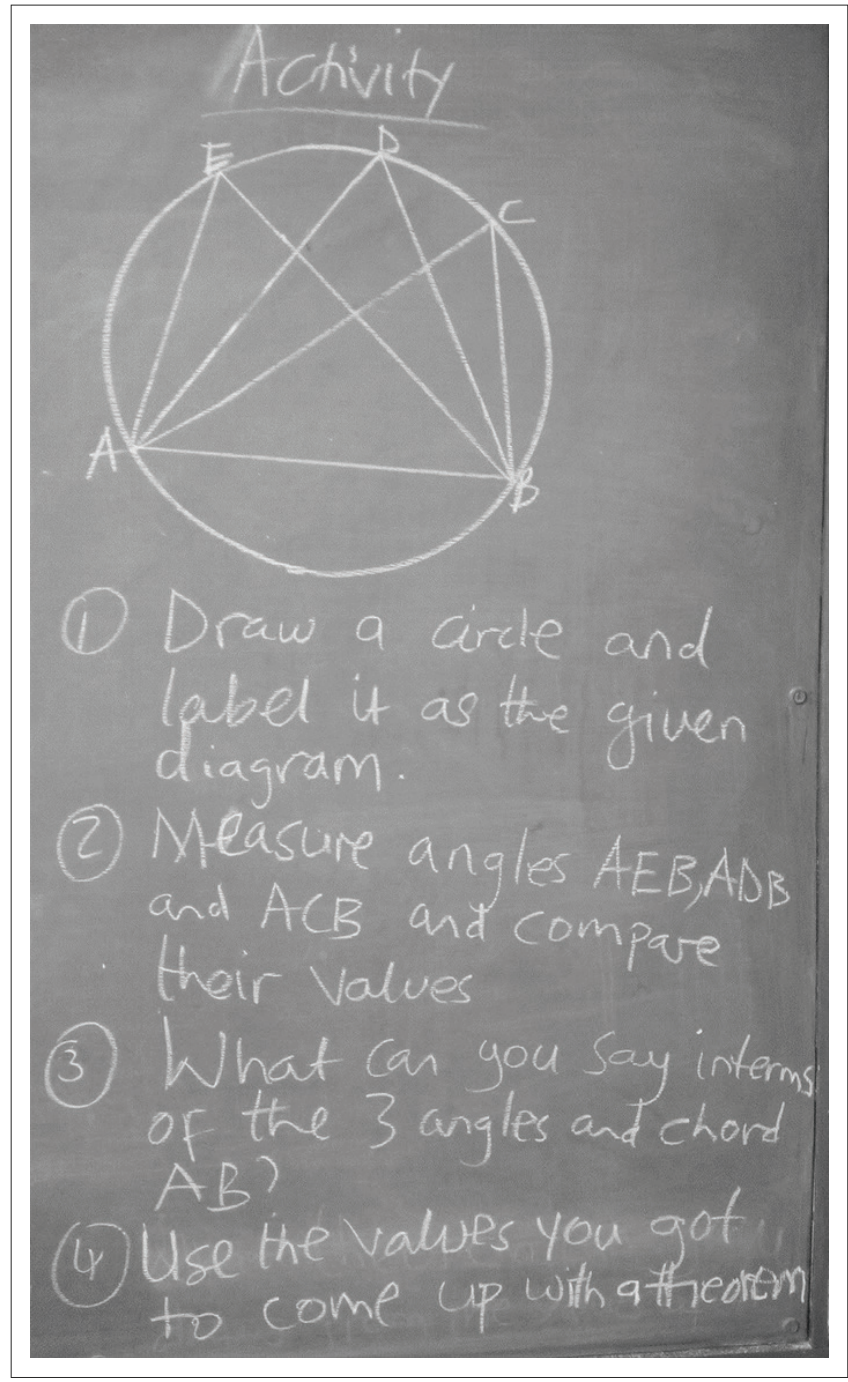

Source: Mwadzaangati, L.E.N. (2017a). An exploration of mathematical knowledge for teaching geometric proofs. Unpublished doctoral dissertation, University of Malawi, Zomba, Malawi (p. 201). Retrieved from http://repository.cc.ac.mw:8080/jspui

FIGURE 5: Empirical exploration task on angle properties of the circle.

As noticed in Figure 6(a), the angles that are subtended by the same arc have already been identified and necessary construction has also been provided (lines $A O$ and $O B$ are already drawn). The learners are required to decide the theorem to be used for developing the proof and to construct proving statements. The example and task set up by John in Figure 6(a) is similar to the one that was set up by Paul under the same object of learning. The only difference was that Paul added labels to the angles in the same segment. He labelled $\angle A D B$ as $x$ and $\angle A C B$ as $y$ and wrote that the task was to prove that $x=y$. Although some of the decisions were already provided by Paul and John, the tasks are still of high cognitive value because the critical part of hypothetical bridging (Cheng \& Lin, 2009) is not disclosed. Hence the task is under the doing mathematics category as it requires learners to identify the hypothetical bridge and make geometric connections to develop the proofs.

To be able to do the task of proving that angles in the same segment are equal using the example in Figure 6(b), the learners are required to identify angles subtended by the 


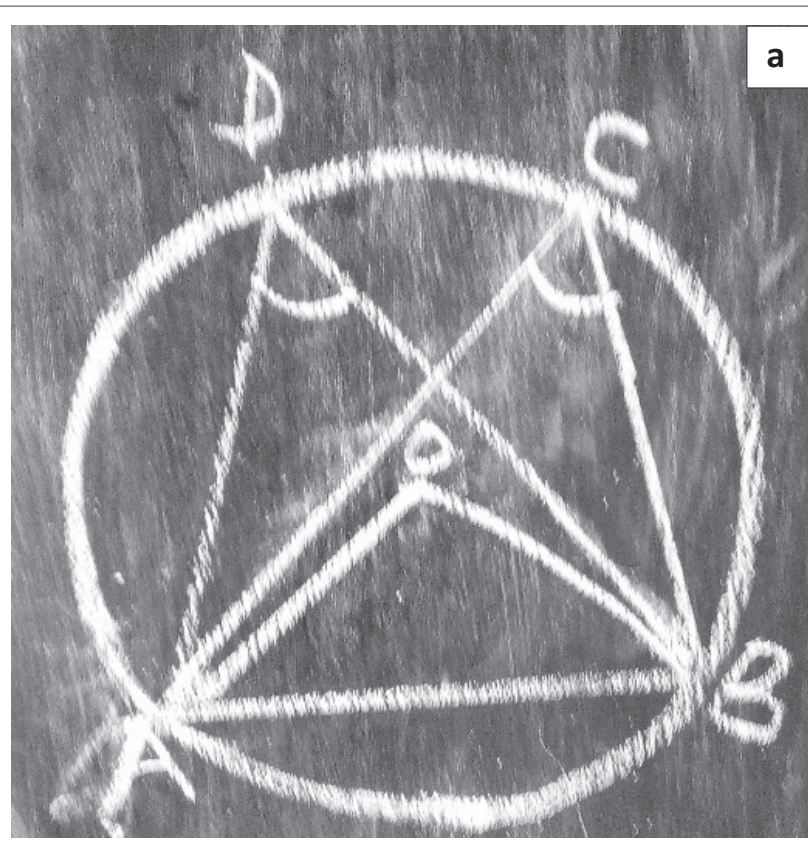

Theorem: Angles in the same segment of a circle are equal. Task: Prove that $\angle A D C$ is equal to $\angle A C B$.

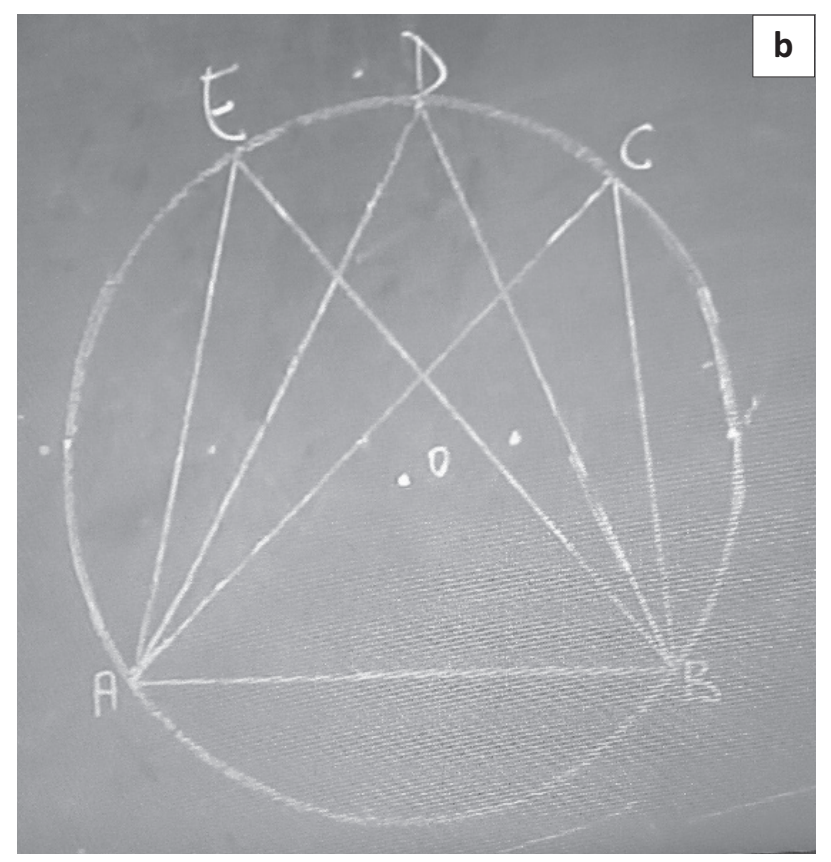

Task: Prove that angles subtended by the same arc at the circumference of a circle are equal (angles in the same segment are equal).

FIGURE 6: Examples and tasks as set up by the teachers in the classroom (a) John's example for formal proof and (b) Kim's task for formal proof.

same arc at the circumference, to decide the construction to be added to the diagram, to decide the hypothetical bridge to use for developing the proof, and to construct proving statements. This implies that Kim's formal proof task is also under the doing mathematics category as there is no hint for deciding the construction to be added to the diagram and the hypothetical bridge to be used. This analysis has shown that the deductive geometric proof development tasks that were set up by the three teachers in their classrooms were similar to those that were set up in the textbook. The analysis has also shown that the formal proof tasks are of high cognitive level because they required learners to make several decisions on angles to be proved, construction to be made and the hypothetical bridge to be used.

\section{Task implementation by Paul}

The lesson observation data showed that during geometric proof development, Paul explained everything that was supposed to be done to develop the proof. For example, when proving angles in the same segment of the circle are equal, he started by showing the learners that angles $x$ and $y$ were the ones that were being subtended by arc $A B$. Then he told the students that they were going develop the proof by using the theorem developed in the previous lesson which states that 'an angle that an arc of a circle subtends at the centre of a circle is twice the angle subtended by the same arc at any point on the circumference of the circle'. This is the way the theorem is stated in the textbook. This shows that Paul did not realise that the theorem was not stated correctly in the textbook. Later on, Paul went ahead explaining and writing the proving statements and their reasons on the chalkboard until he arrived at the conclusion. This shows that despite the task being of a high cognitive level, Paul implemented it at a lower level as learners were not involved in any form of explaining or justifying the truth of the theorem. Although the textbook encouraged the learners to first attempt to develop the formal proof on their own before referring to the proof development approach provided in the textbook, Paul did not give learners an opportunity to express their views on how the proof could be developed. This implies that despite being set up as a high cognitive level task both in the textbook and on the chalk board, the proof task was implemented at a low cognitive level as Paul did not involve the learners in any form of thinking, explaining and exploring of how the proof could be developed. Hence, the mode of task implementation reduced the cognitive level of the task from a high level to a low level (Stein et al., 2009).

\section{Task implementation by John}

John also used an approach of question and answer to teach the learners how to develop the deductive geometric proofs. In all lessons, John provided guidance on the theorems or geometric properties that were applied when developing the formal proofs. For example, when developing the proof using the task in Figure 6(a), John started by telling the learners that the lesson was about proving that angles in the same segment of a circle are equal. He explained that 'angles in the same segment are the angles that are subtended by the same chord or arc at the circumference'. John stated the theorem the way it is stated in the book that he was using (Strides in mathematics 3). However, John's description of angles in the same segment is partially not correct because it has left out an important point that is stated in the textbook. He does not specify that the angles should be in the same segment of the circle. This might imply that John's wording 
or explanation of the theorem was not correct as it implied that the equal angles that are subtended by the same arc might lie in alternate segments as well. After describing angles in the same segment, John engaged the learners in the following conversation:

1. John: So, we start with the first step, what are we given?

2. Student: Circle with centre $O$.

3. John: What else?

4. Student: Chord $A B$.

5. John: Yes, chord $A B$ which is subtending angles $c$ and $d$ at the circumference, and angle $y$ at the centre. This is what we are given [and he writes on the board]. So, what are we asked to prove?

6. Student: Angle $c$ equals angle $d$.

7. John: Yes, this is what we should prove. So, for us to show that these angles are equal, let us consider the theorem we proved yesterday. What theorem did we prove yesterday?

8. Student: Angle at the centre is two times the angle at the circumference.

9. John: Yes, that is true, yesterday we proved that angle at the centre is two times angle at the circumference. So what statements can we come up with using that theorem to prove that angles $c$ and $d$ are equal?

10. Student: Angle $y$ is two times angle $c$, reason is that angle at the centre is two times angle at the circumference.

11. John: Correct [while writing the statement on the chalkboard], what is the other statement?

12. Student: Angle $y$ is two times angle $d$, same reason, angle at the centre is two times angle at the circumference.

The lesson conversation shows that John implemented the task using the question and answer method in a stepwise process. Firstly, he asked the learners to identify the given information (utterances 3-6). Secondly, he asked the learners to identify the statement to prove (utterance 6). Lastly, he involved the learners in constructing the proving sentences (utterance 10-13). The lesson extract shows that learners did not struggle to construct the proving statements. This might be because John had already provided the hint for the hypothetical bridge to be used for developing the proving statements (utterance 10). Since identification of the hypothetical bridge is the critical part of deductive geometric proof development (Cheng \& Lin, 2009), then this shows that the learners were not involved in high cognitive level thinking. According to Smith and Stein (1998), provision of hints that are critical to solving of a task reduces the cognitive level of the task. This implies that the cognitive level of the task was reduced from high level to low level because of the mode of implementation (Charalambous, 2010). Some might argue that John provided the hint with an aim of trying to help the learners to gradually realise how to develop the proof. But Polya (1945) discourages teachers from providing much guidance to support learners; instead he suggests that teachers should ask different types of questions that would support the learners to identify the hypothetical bridge on their own.

\section{Task implementation by Kim}

Kim mainly used group work when teaching the learners to develop proofs for the theorems. The learners would discuss and develop the proofs in their groups and then present them to the whole class. For example, when implementing the task in Figure 6(b), Kim asked the learners to draw a diagram similar to the one that he drew on the chalkboard in their groups and discuss how to develop the proof for the theorem by stating that angles subtended by an arc in the same segment of a circle are equal. As the learners were developing the proof in groups, Kim checked their work and provided some guidance to those learners who experienced difficulties in developing the proof. After about 15 minutes, Kim asked the learners to report their work by giving an oral account regarding how they proved the theorem. The following is a conversation between Kim and students after the group discussions:

13. Student 1: [While pointing at the diagram drawn by Kim] we joined $A B$ at $O$, then Let $\angle A O B$ be $2 y$. So $\angle A E B$ equals $y, \angle A C B$ equals $y$, and $\angle A D B$ is also equal to $y$. Therefore, angles $A E B, A C B$ and $A D B$ are equal.

14. Kim: Why do you say that angles $A E B, A C B$ and $A D B$ are equal to $y$ ?

15. Student 1 Because angle at the centre is two times angle at the circumference, so if we have $2 y$ here [pointing at $\angle A O B]$ then this is $y$ [pointing at $\angle A E B]$, this is $y$ [pointing at $\angle A C B]$, this is also $y$ [pointing at $\angle A D B]$

16. Kim: Yes that is true, but you need to remember to justify your statements with reasons. Did you all use this approach, or is there any group with a different approach?

17. Student 2: Yes, we joined $A O$ and $B O$. Then two times $\angle A E D$ equals $\angle A O B$, two times $\angle A D B$ equals $\angle A O B$, and two times $\angle A C B$ equals $\angle A O B$. The reason is the same, angle at the centre is equal to two times angle at the circumference.

18. Kim: Yes, that is also a correct method. So, apart from the two ways that have been presented, any group with a different way?

19. Student 3: Yes, we joined $A O$ and $B O, \angle A E B$ equals half $\angle A O B$, reason is angle at the circumference is equal to half angle at the centre. $\angle A C B$ equals half $\angle A O B$ same reason, $\angle A D B$ equals half $\angle A O B$, same reason, therefore angles $A E B$, $A C B$ and $A D B$ are equal.

The lesson conversation shows that Kim involved the learners in exploring the proof of the theorem and the learners came up with their own ways of developing the proof. All learners made the same construction on their diagrams, and they also used the same property - which states that the angle subtended by an arc at the centre is twice the angle subtended by the same arc at the circumference of the circle - as their hypothetical bridge (utterances 15, 17 and 19). This was the theorem that the learners proved in the previous lesson. Despite making the same construction on the diagram and using the same hypothetical bridge, the proofs were developed using slightly different approaches (utterances 15, 
17 and 19). Although the proof explained by student 1 (utterance 15) is similar to the one presented in the Strides in mathematics 3 textbook, the letters that have been used are different. This implies that when the learners explored how to develop the proof, they made several connections with their previous knowledge. Furthermore, the learners were able to explain their proofs clearly, and they provided good justifications for their proving statements. This shows that Kim implemented the task in a manner that involved learners' high cognitive levels of thinking, hence the task maintained its high cognitive level during implementation (Stein et al., 2009).

\section{Discussion of the findings}

The findings reveal that the textbook that the teachers used for teaching deductive geometric proof development contained both empirical exploration and formal proof tasks which were of a high cognitive level. The empirical exploration tasks promoted discovering of proofs as they required learners to deduce theorems from the results of an empirical activity. The formal proof tasks promoted verification, explanation and systemisation as they required learners to identify a hypothetical bridge for constructing logically sequenced proving statements (Cheng \& Lin, 2009; De Villiers, 1999). This shows that the textbook has included rich opportunities for learners to engage in doing mathematics (Stein et al., 2009) and in reasoning and proving in a coherent manner (Stylianides, 2014). Despite the limitation that the empirical task set up in the textbook might lead to misconception that it is acceptable to generalise from a single case in mathematics, it is worth acknowledging that the textbook attempted to provide opportunities for empirical explorations.

Some might argue that the empirical exploration tasks set up in the textbook were poorly designed because they mainly require the use of pencil and paper and not computer software. It is argued that computer software can enhance learners' ability in developing geometric proofs better than pencil and paper tasks because they organise and promote learners' thinking (Mariotti, 2000). It has also been observed that pencil and paper diagrams are difficult for learners to grasp because they might deviate learners' focus from properties of the diagram to properties of construction (Mariotti, 2000). Despite this flaw, pencil and paper tasks fit well with the context in which the study was undertaken. As already explained, Malawian secondary schools operate under resource constrained conditions where textbooks are the most available teaching and learning resource. The textbook tasks might have been designed in this way to enable teachers and learners to use the resources that are accessible to them, for example mathematical sets, pencils and paper. The instructions for doing the empirical exploration tasks might serve as attempts to address limitations of pencil and paper tasks. As such, a didactical design of the textbooks fits well with the Malawian context. The instructional approach used in the textbook is called presenting a proof problem as an experimental problem and a formal proof (Ding \& Jones, 2009). This approach helps learners to understand the formal proof and to appreciate the discovery function of proof in mathematics through the new problem-solving strategies that they devise and the reflections that they make on the developed proofs (De Villiers, 2012; Ding \& Jones, 2009; Jones et al., 2009). The task setup approach used in the textbook is also supported by Hanna (2000) who suggests that during mathematical proof development, learners should be provided with opportunities to explore different paths to the solution outcome by using a combination of inductive and deductive reasoning processes.

Kim provided learners with rich opportunities to explore and understand the proof development process and its advantages by setting up and implementing tasks similar to the textbook tasks. The findings from Kim support the argument that textbooks are supposed to have similarity with classroom lessons (Ronda \& Adler, 2016). The approach that was used by Kim is also recommended by Ding and Jones (2009) who explain that helping learners to understand why a proof works, and then using that understanding to further generalise or specialise the result, is one way of encouraging learners to understand and appreciate the discovery function of mathematical proofs.

However, although the textbook has presented geometric proof development as both an empirical and formal process, Paul and John only presented the formal proofs in the classroom. This implies that Paul and John did not utilise the textbook guidance regarding learners' tasks for supporting understanding of geometric proof development. This finding agrees with Stylianides (2014) who argues that equipping teachers with textbooks containing high quality proving tasks does not necessarily imply that the teachers will implement the tasks presented in the textbooks faithfully. This means that although high quality mathematics textbooks have a potential of improving learners' understanding of geometric proof development (Otten et al., 2014), the realisation of this potential depends on how teachers implement the tasks in the classroom.

The findings also showed that the formal proof tasks that were set up by Paul and John in the classroom were similar to those that were in the textbook, hence they were of a high cognitive level. However, the tasks decreased in their cognitive level because learners were not involved in activities that would enhance their reasoning. As Charalambous (2010) argues, a high level task can decline in its cognitive level when learners are not involved in exploration and explanation of their procedures during task implementation. Charalambous (2010) argues that the teacher's way of explaining and representing mathematical tasks largely depends on the breadth and depth of their conceptual understanding of mathematics. This agrees with the findings in Mwadzaangati (2017a) which showed that John and Paul displayed some limitations in conceptual understanding of the deductive geometric proof development 
process while Kim displayed competencies in deductive geometric proof development (Mwadzaangati, 2017a, 2017b). This suggests that depending on their conceptual understanding of geometric proof development, teachers can either elevate or decrease a task's cognitive demand during either task setup or task implementation.

\section{Conclusion}

This study examined similarities and differences between deductive geometric proof development tasks as set up in the textbook, and as set up and implemented by teachers in the classroom. The findings showed that the geometric proof tasks in the textbook were set up at a high cognitive level and included explorations and explanations. The textbook contained two types of deductive geometric proof development which can be categorised as empirical exploration tasks and formal proof tasks. Empirical exploration tasks were those that required the learners to draw diagrams, do some measurements on either lines or angles of the diagram and deduce a theorem. Formal proof development tasks required the learners to explore how to develop the formal proof. Despite the availability of both empirical exploration tasks and formal proof tasks, John and Paul involved the learners in formal proof tasks only. Kim followed the textbook procedure by involving learners in both empirical exploration tasks and formal proof tasks. In terms of the formal proof tasks, the findings showed that all three teachers set up high cognitive level tasks in the classroom but their modes of implementation were different. Kim involved the learners in exploring and explaining how to develop the proofs, hence he maintained the high cognitive level of the tasks during implementation. Paul and John implemented the formal proof tasks at low cognitive level as they provided the learners with hints for the most critical stages of deductive proof development. This study, therefore, concludes that ability to support learners' understanding in deductive geometric proof development does not only depend on the availability of a welldesigned textbook, but also depends on the teachers' conceptual ability to use the textbook effectively. Since the data analysed in this study were only from the teachers' lessons and the textbook content, I suggest further studies to increase our understanding of the reasons behind the choices that teachers make during task setup and implementation in the classroom through other methods of data collection like interviewing the teachers. Since naming and word use and legitimations were also observed to be problematic for the teachers, future research might also focus on examining how teachers explain geometric concepts and legitimise them during the lesson.

\section{Acknowledgement}

\section{Competing interests}

I declare that I have no financial or personal relationships that may have inappropriately influenced me in writing this article.

\section{Author's contributions}

I declare that I am the sole author of this article.

\section{Funding information}

This study was kindly funded by Norwegian Programme for Capacity Building in Higher Education and Research for Development (NORHED) under Improving Quality and Capacity of Mathematics Teacher Education in Malawi Project.

\section{Data availability statement}

Data sharing is not applicable to this article as the author did not seek consent from the participants to share the data.

\section{Disclaimer}

The views and opinions expressed in this article are those of the author and do not necessarily reflect the official policy or position of any affiliated agency of the author.

\section{References}

Adler, J., \& Ronda, E. (2015). A framework for describing mathematics discourse in instruction and interpreting differences in teaching. African Journal of Research in Mathematics, Science and Technology Education, 19(3), 237-254. https://doi.org /10.1080/10288457.2015.1089677

Battista, M.T. (2007). The development of geometric and spatial thinking. In F.K. Lester (Ed.), Second handbook of research on mathematics teaching and learning (pp. 843-908). Charlotte, NC: Information Age.

Berg, B.L. (2001). Qualitative research methods for the social sciences (4th ed.). Boston, MA: Allyn and Bacon.

Bergwall, A. (2017). Conceptualizing reasoning-and-proving opportunities in textbook expositions: Cases from secondary calculus. In T. Dooley \& G. Gueudet (Eds.) Proceedings of the Tenth Congress of the European Society for Research in Mathematics Education (pp. 91-98). Dublin: ERME. Retrieved from https://hal. archives-ouvertes.fr/CERME10/public/CERME10_Complete.pdf

Bowie, L. (2013). Tensions in the transition from informal to formal geometry. In S. Kwofie, M.B. Ogunnyi, O. Amosun, K.R. Langenhoven, \& S. Dinie (Eds.), Proceedings of the 21st Conference of the Southern African Association for Research in Mathematics, Science and Technology Education (pp.104-115). Cape Town: SAARMSTE.

Bryman, A. (2008). Social research methods (3rd ed.). Oxford: Oxford University Press.

Cheng, F., \& Lin, F. (2009). Developing learning strategies for enhancing below average students' ability in constructing multi-steps geometry proof. In F.-L. Lin, F.-J. Hsieh, G. Hanna, \& M. de Villiers (Eds.), Proceedings of the ICMI Study 19 Conference: Proof and Proving in Mathematics Education (Vol. 1, pp.124-129). Taipei: National Taiwan Normal University. Retrieved from http://140.122.140.1/ icmi19/files/ Taiwan Normal

Charalambous, C.Y. (2010). Mathematical knowledge for teaching and task unfolding: An exploratory study. The Elementary School Journal, 110(3), 247-278. Retrieved An exploratory study. The Elementary School Journal,
from https://www.jstor.org/stable/10.1086/648978

Cohen, L., Manion, L., \& Morrison, L. (2007). Research methods in education (6th ed.). London: Routledge.

Crowley, M.L. (1987). The Van Hiele model of the development of geometric thought in learning and teaching geometry, K-12. In M.M. Lindquist (Ed.), Yearbook of the National Council of Teachers of Mathematics (pp. 1-16). Reston, VA: NCTM.

De Villiers, M. (1999). Rethinking proof with sketchpad. Emeryville, CA: Key Curriculum Press.

De Villiers, M. (2012). An illustration of the explanatory and discovery functions of proof. Pythagoras, 33(3), Art. \#193, 8 pages. https://doi.org/10.4102/pythagoras. v33i3.193

Ding, L., \& Jones, K. (2009) Instructional strategies in explicating the discovery function of proof for lower secondary school students. In F.-L. Lin, F.-J. Hsieh, G. Hanna, \& M. De Villiers (Eds.), Proceedings of the ICMI Study 19 Conference: Proof and Proving in Mathematics Education (Vol. 1, pp. 136-141). Taipei: National Taiwan Normal University. Retrieved from http://140.122.140.1/ icmi19/files/Volume_1.pdf

Fujita, T., Jones, K., \& Kunimune, S. (2009). The design of textbooks and their influence on students' understanding of 'proof' in lower secondary school. In F.-L. Lin, F.-J. Hsieh, G. Hanna, \& M. De Villiers (Eds.), Proceedings of the ICMI Study 19 Conference: Proof and Proving in Mathematics Education (Vol. 1, pp.172-177). Taipei: National Taiwan Normal University. Retrieved from http://140.122.140.1/ icmi19/files/Volume_1.pdf

Hanna, G. (2000). Proof, explanation and exploration: An overview. Educational Studies in Mathematics, 44(1), 5-23. https://doi.org/10.1023/A:1012737223465

Hau, S., \& Saiti, F. (2002). Strides in mathematics 3. Balantyre: Longman Malawi.

Heinze, A. (2004). The proving process in mathematics classroom, methods and results of a video study. In M.J. Hines \& A.B. Fuglestad (Eds.), Proceedings of the 28th Conference of the International Group for the Psychology of Mathematics Education (Vol. 3, pp. 41-48). Bergen: PME. Retrieved from https://files.eric. ed.gov/fulltext/ED489632.pdf 
Henningsen, M., \& Stein, M.K. (1997). Mathematical tasks and student cognition Classroom-based factors that support and inhibit high-level mathematical thinking and reasoning. Journal for Research in Mathematics Education, 28(5), 524-549.

Jones, K. (2002), Issues in the teaching and learning of geometry. In L. Haggarty (Ed.), Aspects of teaching secondary mathematics: Perspectives on practice (pp. 121-139). London: Routledge Falmer.

Jones, K., Kunime, S., Kumakura, H., Matsumoto, S., Fujita, T., \& Ding, L. (2009) Developing pedagogical approaches for proof. Learning from teaching in the West and in the East. In F.-L. Lin, F.-J. Hsieh, G. Hanna, \& M. De Villiers (Eds.), Proceeding of the ICMI Study 19 Conference: Proof and Proving in Mathematics Education (Vol. 1, pp. 232-237). Taipei: National Taiwan Normal University. Retrieved from http://140.122.140.1/ icmi19/files/Volume 1.pdf

Kunimune, S., Fujita, T., \& Jones, K. (2010). Strengthening students' understanding of 'proof' in geometry in lower secondary school. In V. Durand-Guerrier, S. Soury-Lavergne, \& F. Arzarello (Eds.), Proceedings of the Sixth Congress of the European Society for Research in Mathematics Education (pp. 756-765). Lyon: ERME Retrieved from https://ife.ens-lyon.fr/publications/edition-electronique/ cerme6/cerme6.pdf

Malawi National Examinations Board. (2013). Chief examiners' reports for Junio Certificate Examinations and Malawi Senior Certificate Mathematics Examinations. Unpublished reports. Zomba: MANEB.

Mariotti, M.A. (2000). Introduction to proof: The mediation of a dynamic software environment. Educational Studies in Mathematics, 44, 25-53.

Marton, F., \& Tsui, A.B.M. (2004). Classroom discourse and the space of learning. Mahwah, NJ: Lawrence Erlbaum Associates.

Mellor, K., Clark, R., \& Essien, A.A. (2018). Affordances for learning linear functions: A comparative study of two textbooks from South Africa and Germany. Pythagoras, 39(1), a378. https://doi.org/10.4102/pythagoras.v39i1.378

Ministry of Education, Science and Technology. (2013). Republic of Malawi syllabus for Mathematics Forms 3 and 4. Zomba: Malawi Institute of Education.

Mwadzaangati, L.E.N. (2017a). An exploration of mathematical knowledge for teaching geometric proofs. Unpublished doctoral dissertation, University of Malawi, Zomba, Malawi. Retrieved from http://repository.cc.ac.mw:8080/jspui

Mwadzaangati, L.E. (2017b). Examining Malawian secondary school teachers' conceptualisati on of geometric proving. In M.K. Mhlolo, S.N. Matoti, \& B. Fredericks (Eds.), Proceedings of the 25th Annual Meeting of the Southern African Association for Research in Mathematics, Science and Technology Education (pp. 116-131). Bloemfontein: SAARMSTE. Retrieved from http://www.saarmste.org/ images/Conference Proceedings/SAARMSTE2017-Central University_Tech Bloemfontein/SAARMSTE\%20Long\%20paper\%20Book\%20Electronic.pdf

Otten, S., Males, M.M., \& Gilbertson, N.J. (2014). The introduction of proof in secondary geometry textbooks. International Journal of Educational Research, 64 107-118. https://doi.org/10.1016/j.ijer.2013.08.006
Otten, S., Gilbertson, N.J., Males, M.M., \& Clark, D.L. (2011). Reasoning-and-proving in geometry textbooks: what is being proved? In L.R. Wiest \& T. Lamberg (Eds.) Proceedings of the 33rd Annual Meeting of the North American Chapter of the International Group for the Psychology of Mathematics Education (pp. 347-355). International Group for the Psychology of Mathematics Education (pp. 347-355). pmenaproceedings/PMENA $\% 2033 \% 202011 \% 20$ Proceedings.pdf

Polya, G. (1945). How to solve it? A new aspect of mathematical method. Princeton, $\mathrm{NJ}$ : Princeton University Press.

Ronda, E., \& Adler, J. (2016). Mining mathematics in textbook lessons. Internationa Journal of Science and Mathematics Education, 15(6), 1097-1114. https://doi. org/10.1007/s10763-016-9738-6

Smith, M.S., \& Stein, M.K. (1998). Selecting and creating mathematical tasks: From research to practice. Mathematics Teaching in the Middle School, 3(1), 344-350. Retrieved from https://www.jstor.org/stable/41180423

Stein, M.K., Grover, B.W., \& Henningsen, M. (1996). Building student capacity for mathematical thinking and reasoning: An analysis of mathematical tasks used in reform classrooms. American Educational Research Journal, 33, 455-488. Retrieved from https://www.jstor.org/stable/1163292

Stein, M.K., Smith, M.S., Henningsen, M.A., \& Silver, E.A. (2009). Implementing standards-based mathematics instruction: A casebook for professional development ( 2 nd ed.). New York, NY: Teachers College Press.

Stylianides, G.J. (2005). Investigating students' opportunities to develop proficiency in reasoning and proving: A curricular perspective. Unpublished doctoral dissertation, University of Michigan, Ann Arbor, USA. Retrieved from http://hdl. handle.net/2027.42/125230

Stylianides, G.J. (2009). Reasoning-and-proving in school mathematics textbooks. Mathematical Thinking and Learning, 11(4), 258-288. https://doi. org/10.1080/10986060903253954

Stylianides, G.J. (2014). Textbook analyses on reasoning-and-proving: Significance and methodological challenges. International Journal of Education Research, 64, 63-70. https://doi.org/10.1016/j.ijer.2014.01.002

Thompson, D.R., Senk, S.L., \& Johnson, G.J. (2012). Opportunities to learn reasoning and proof in high school mathematics textbooks. Journal for Research in Mathematics Education, 43(3), 253-295. Retrieved from https://www.jstor.org/ stable/10.5951/jresematheduc.43.3.0253

Usiskin, Z. (1982). Van Hiele levels and achievement in secondary school geometry. Chicago, IL: University of Chicago. Retrieved from https://files.eric.ed.gov/ fulltext/ED220288.pdf

Van Hiele, P.M. (1999). Developing geometric thinking through activities that begin with play. Teaching Children Mathematics, 5(6), 310-315. Retrieved from https:// www-jstor-org.ez.sun.ac.za/stable/41198852

Yin, R.K. (2009). Case study research design methods (4th ed.). Los Angeles, CA Sage. 